\title{
M2 macrophage-derived exosomal microRNAs inhibit cell migration and invasion in gliomas through PI3K/AKT/mTOR signaling pathway
}

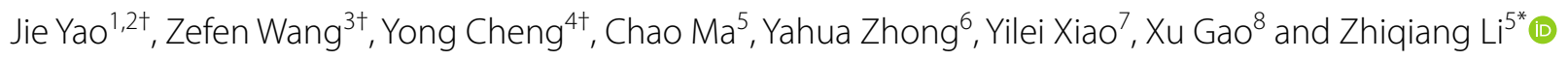

\begin{abstract}
Background: Glioma, the most common primary brain tumor, account Preparing figures for 30 to $40 \%$ of all intracranial tumors. Herein, we aimed to study the effects of $\mathrm{M} 2$ macrophage-derived exosomal microRNAs (miRNAs) on glioma cells.

Methods: First, we identified seven differentially expressed miRNAs in infiltrating macrophages and detected the expression of these seven miRNAs in M2 macrophages. We then selected hsa-miR-15a-5p (miR-15a) and hsa-miR92a-3p (miR-92a) for follow-up studies, and confirmed that miR-15a and miR-92a were under-expressed in M2 macrophage exosomes. Subsequently, we demonstrated that M2 macrophage-derived exosomes promoted migration and invasion of glioma cells, while exosomal miR-15a and miR-92a had the opposite effects on glioma cells. Next, we performed the target gene prediction in four databases and conducted target gene validation by qRT-PCR, western blot and dual luciferase reporter gene assays.
\end{abstract}

Results: The results revealed that miR-15a and miR-92a were bound to CCND1 and RAP1B, respectively. Western blot assays demonstrated that interference with the expression of CCND1 or RAP1B reduced the phosphorylation level of AKT and mTOR, indicating that both CCND1 and RAP1B can activate the PI3K/AKT/mTOR signaling pathway.

Conclusion: Collectively, these findings indicate that M2 macrophage-derived exosomal miR-15a and miR-92a inhibit cell migration and invasion of glioma cells through PI3K/AKT/mTOR signaling pathway.

Keywords: M2 macrophage, Exosome, hsa-miR-15a-5p, hsa-miR-92a-3p, Glioma, PI3K/AKT/mTOR

\section{Introduction}

Gliomas, one of the most common types of primary brain tumors, arise from the gluey supportive cells that surround nerve cells and help them function $[1,2]$. Despite

\footnotetext{
*Correspondence: lizhiqiang@whu.edu.cn

${ }^{\dagger}$ Jie Yao, Zefen Wang and Yong Cheng are joint first authors

${ }^{5}$ Department of Neurosurgery, Zhongnan Hospital of Wuhan University,

No 169 Donghu Road, Wuhan 430071, Hubei, China

Full list of author information is available at the end of the article
}

an increased molecular understanding of gliomas and advances in treatment options including surgery, radiation therapy, chemotherapy, and targeted therapy, almost all (>90\%) malignant gliomas still recur, most commonly within $3 \mathrm{~cm}$ of the original tumor margin $[3,4]$. Once a relapse is diagnosed, the survival time is short, usually 3-6 months [5]. Therefore, there is an urgent need to find potential biomarkers and effective treatment strategies to reduce malignant gliomas characterized by low survival rates. 
It is well established that tumor microenvironment plays a critical role in promoting tumor growth and metastasis $[6,7]$. Tumor-associated macrophages (TAM) are the most abundant myeloid cells infiltrating the tumor microenvironment $[8,9]$. Activated macrophages are generally classified as M1/M2 dichotomy, which are two extremes in the functional state spectrum $[10,11]$. Th1 cytokine-induced M1 macrophages have pro-inflammatory and antitumor activities, while Th2 cytokinedriven M2 macrophages increase angiogenesis and show tumor-promoting functions [12]. In recent studies, M2 macrophages have been proven to promote glioma proliferation and migration abilities [13, 14].

Exosomes, small membrane vesicles containing mRNAs, microRNAs (miRNAs), long noncoding RNAs and proteins, play a vital role in intercellular communication by delivering their contents to recipient cells $[15,16]$. Lan et al. elucidated that M2 macrophages promote the migration and invasion of colorectal cancer cells by M2 macrophagederived exosomes which show high expression levels of miR-21-5p and miR-155-5p [17]. Zheng et al. demonstrated that the exosome-mediated transfer of functional ApoE protein from M2 macrophages to the tumor cells promotes the migration of gastric cancer cells [18]. However, the role of M2 macrophage-derived exosomes in regulating glioma progression and metastasis remains largely unknown.

In the present study, differentially expressed miRNAs between peripheral blood mononuclear cells and infiltrating macrophages were identified and their expression levels were investigated in M2 macrophages and in exosomes derived from M2 macrophages. Next, we evaluated the effects of M2 macrophage-derived exosomes and exosomal hsa-miR-15a-5p (miR-15a) and hsa-miR92a-3p (miR-92a) on migration and invasion of glioma cells. Subsequently, target gene prediction and validation of miR-15a and miR-92a were implemented. Finally, western blot analysis was performed to explore the relationship between the expression of target genes and $\mathrm{PI} 3 \mathrm{~K} / \mathrm{AKT} / \mathrm{mTOR}$ signaling pathway.

\section{Results}

\section{Identification and verification of key miRNAs in M2} macrophage-derived exosomes

We obtained the dataset GSE51332 from GEO database, which included four cases of peripheral blood mononuclear cells and four cases of infiltrating macrophages in glioma patients. By analyzing the miRNA expression in the samples through GEO2R (Fig. 1a), we identified seven miRNAs that were most significantly differentially expressed in infiltrating macrophages (Table 1). By visualizing the expression in the samples through ClusterVis, we obtained the heat maps of the expression profiles of these seven miRNAs (Fig. 1b).
Subsequently, we tested the expression levels of biomarkers in macrophages with different differentiation states. The results of western blot assays (Fig. 1c) showed that CD206 (M2 macrophage phenotype marker gene) was significantly over-expressed in M2 macrophages, and the expression of CD68 (macrophage marker gene) was not significantly different in M0, M1 and M2 macrophages. By qRT-PCR detection, we found that TNF-a, IL-12 and iNOS (M1 macrophage phenotype marker genes) were up-regulated in M1 macrophages compared with M0 macrophages (Fig. 1d). IL-10, TGF- $\beta$, and CD206 (M2 macrophage phenotype marker genes) were found to be highly expressed in M2 macrophages compared with M0 macrophages (Fig. 1e). Then we induced macrophage differentiation according to the tested markers through in vitro cell experiments and measured the expression of these seven miRNAs using qRT-PCR. The results elucidated that miR-15a and miR-92a were significantly under-expressed in M2 macrophages (Fig. 1f), consistent with the expression levels in GEO. However, no obvious upregulated expression levels were shown in the detection of miR-574, miR-4792 and miR-34a, which was not consistent with their expressed results predicted in GEO. Therefore, we selected the obviously downregulated miRNAs, miR-15a and miR-92a, as the next research objects.

In order to verify the expression of miR-15a and miR-92a in exosomes derived from M2 macrophages, exosomes need to be extracted from M2 macrophages. Thus, we collected the culture supernatant of M2 macrophages and THP-1 cells which were used as the control group. According to the TEM image obtained in JEM-2010 HT transmission electron microscope (Fig. 1g), the supernatant of M2 macrophage cell culture contained exosomes, of which the shape was solid and dense. Besides, analysis of size distribution of exosomes was assayed by NTA. As shown in Fig. 1h, the isolated exosomes had a predominant size of 70-120 nm. Exosomes were then extracted and the expression levels of CD9, CD63, and TSG101 (biomarkers of exosomes) were determined by western blot assays. The results showed that the protein levels of TSG101, CD63 and CD81 were significantly increased in the Exo group (Fig. 1i), while the protein levels of Calnexin was evidently diminish in the Exo group compared with control group (Additional file 1: Figure S1), which further confirmed the successful extraction of exosomes. Then we collected the culture supernatants of macrophages with different differentiation states, extracted the exosomes, and examined the expression of miR-15a and miR-92a. As shown in Fig. $1 \mathrm{j}$ and $\mathrm{k}, \mathrm{miR}-15 \mathrm{a}$ and $92 \mathrm{a}$ were underexpressed in M2 macrophage exosomes, and their downregulation multiples were 0.48 and 0.58 , respectively. 


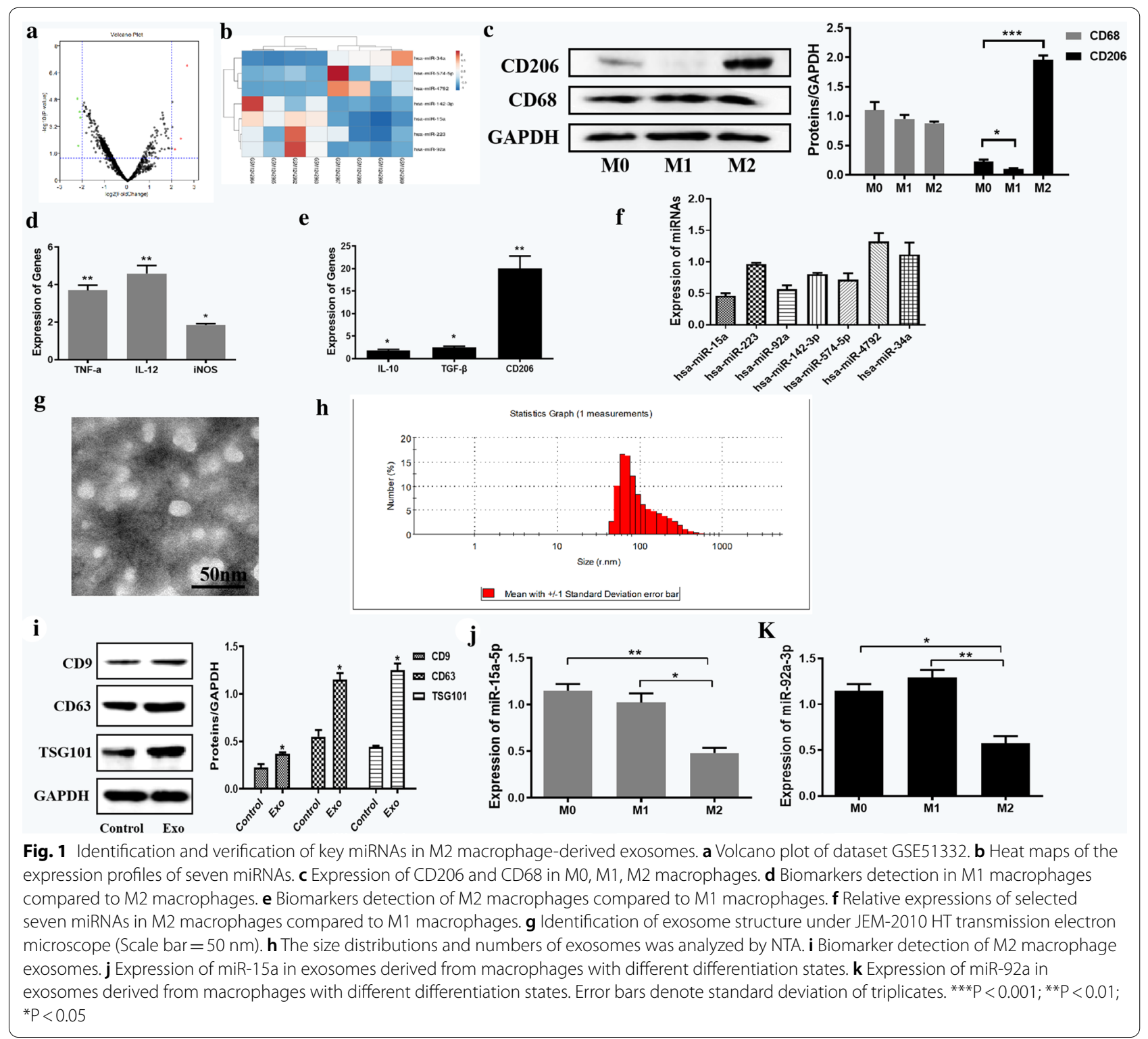

Table 1 Information of differentially expressed miRNAs

\begin{tabular}{lcc}
\hline miRNA ID & Log $_{2}$ FC & P value \\
\hline hsa-miR-15a & -2.24935 & $1.27 \mathrm{E}-05$ \\
hsa-miR-223 & -2.21532 & $8.15 \mathrm{E}-03$ \\
hsa-miR-92a & -2.14024 & $7.60 \mathrm{E}-05$ \\
hsa-miR-142-3p & -2.11088 & $1.71 \mathrm{E}-04$ \\
hsa-miR-574-5p & 2.10026 & $1.35 \mathrm{E}-02$ \\
hsa-miR-4792 & 2.36518 & $2.96 \mathrm{E}-03$ \\
hsa-miR-34a & 2.65544 & $1.36 \mathrm{E}-07$ \\
\hline
\end{tabular}

Therefore, miR-15a and miR-92a were selected as key miRNAs for subsequent research.

\section{M2 macrophage-derived exosomes promote migration and invasion of glioma cells}

With an aim to investigate the effect of exosomes derived from M2 macrophages on glioma cells, scratch wound healing and transwell assays were employed. We added the extracted exosomes of M0, M1 and M2 macrophages to glioma cells, respectively. The transverse migration ability of glioma cells was examined 


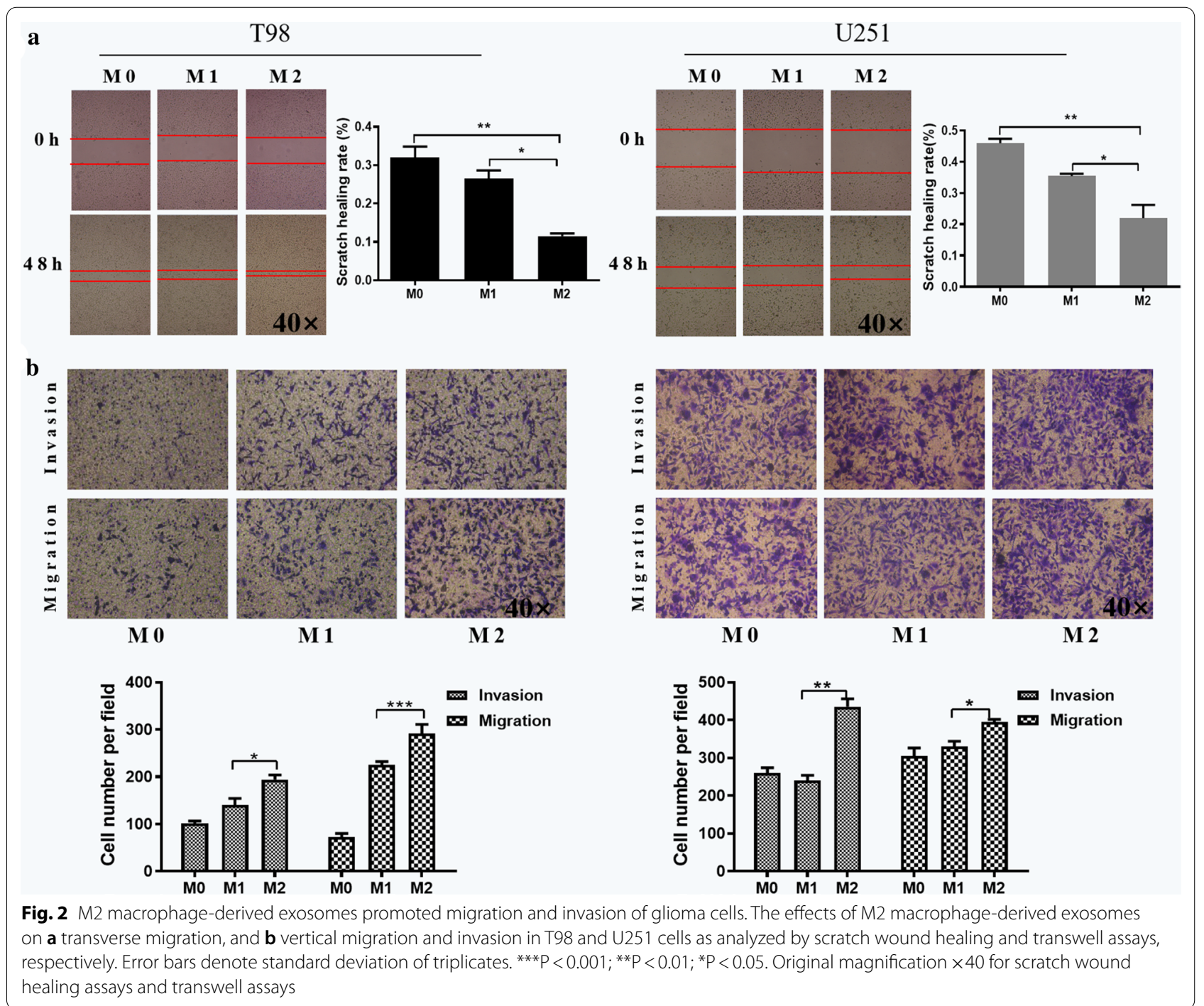

by scratch wound healing assays in T98 and U251 cell lines. It can be seen from Fig. 2a that the scratch healing rate of cells with M2 macrophage exosomes was faster than that of the M0 and M1 groups $(\mathrm{P}<0.05)$. We obtained similar results in U251 cell line (Fig. 2a), indicating that exosomes derived from M2 macrophages can promote transverse migration of glioma cells.

The transwell assays were applied to investigate whether M2 macrophage exosomes could promote the vertical migration and invasion of glioma cells. We found that the number of migrating and invasive cells was significantly increased in M2 group compared with M0 and M1 groups in T98 cells (Fig. 2b). We obtained similar results in U251 cell line (Fig. 2b), suggesting that exosomes derived from M2 macrophages can promote vertical migration and invasion of glioma cells.
Taken together, these findings elucidated that M2 macrophage exosomes can promote migration and invasion of glioma cells.

\section{Exosomal miR-15a and miR-92a inhibit migration and invasion of glioma cells}

The foregoing results revealed that miR-15a and miR92a were under-expressed in M2 macrophage exosomes and that exosomes could promote the migration and invasion of glioma cells. Therefore, we speculated that miR-15a and miR-92a might have an effect on glioma cells. After transfection of miR-15a and miR-92a into M2 macrophages, we collected cell culture supernatant and extracted exosomes. The results of qRT-PCR revealed that the expression of miR-15a was up-regulated about 4.9 times in M2 macrophage exosomes, and miR-92a was 
up-regulated about 7.0 times (Additional file 1: Figure S2), indicating that we successfully over-expressed miR15a and miR-92a in M2 macrophage exosomes.

Subsequently, we reconnoitered the effects of exosomal miR-15a and miR-92a on the migration and invasion of glioma cells. We transfected miR-15a, miR-92a and mimic NC into M2 macrophages, collected cell culture supernatant $48 \mathrm{~h}$ later, extracted exosomes, and added them to T98 and U251 cell lines, respectively. The results from scratch would healing and transwell assays indicated that miR-15a over-expression inhibited the transverse migration of T98 and U251 cells (Fig. 3a, P<0.05), as well as vertical migration and invasion (Fig. 3c, $\mathrm{P}<0.05$ ). We obtained similar results of miR-92a overexpression in T98 and U251 cell lines (Fig. 3b, d, P $<0.05$ ).
Collectively, exosomal miR-15a and miR-92a were found to inhibit migration and invasion of glioma cells.

\section{Target gene prediction}

To identify the target genes of miR-15a and miR-92a, picTar, miRanda, targetScan and PITA databases were used for prediction. A total of 304 target genes of miR-15a were obtained by intersecting the predicted target genes from the four online databases (Additional file 1: Figure S3A). Through STRING and Cytoscape, we found ten hub genes from the 304 target genes of miR-15a (Additional file 1: Figure S3B). Then we checked the expression of these ten hub genes in glioma and adjacent tissues in GEPIA. The results showed that CCND1, CDC42, RAF1, and CHEK1 were highly expressed in gliomas (Fig. 4a).

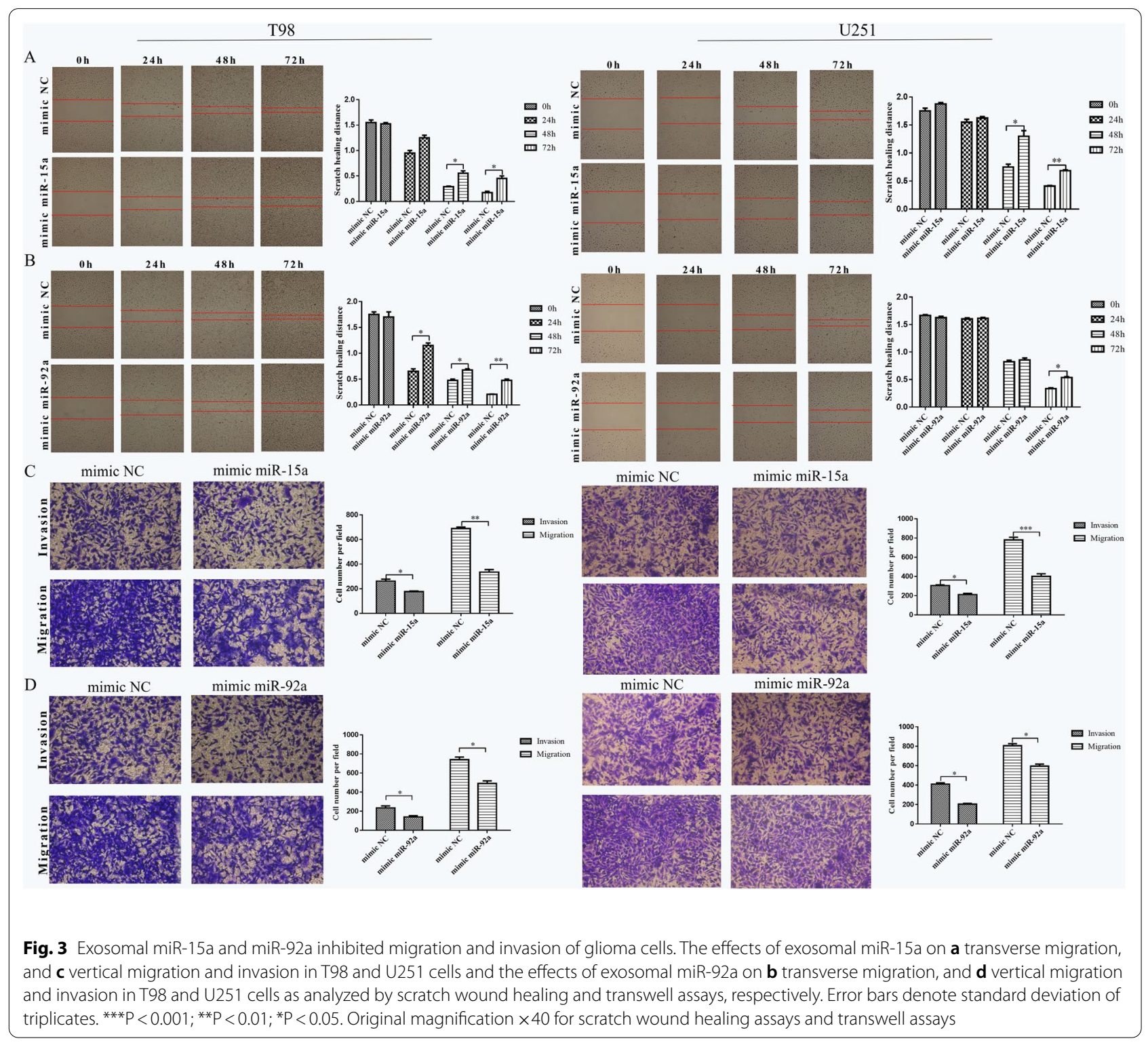




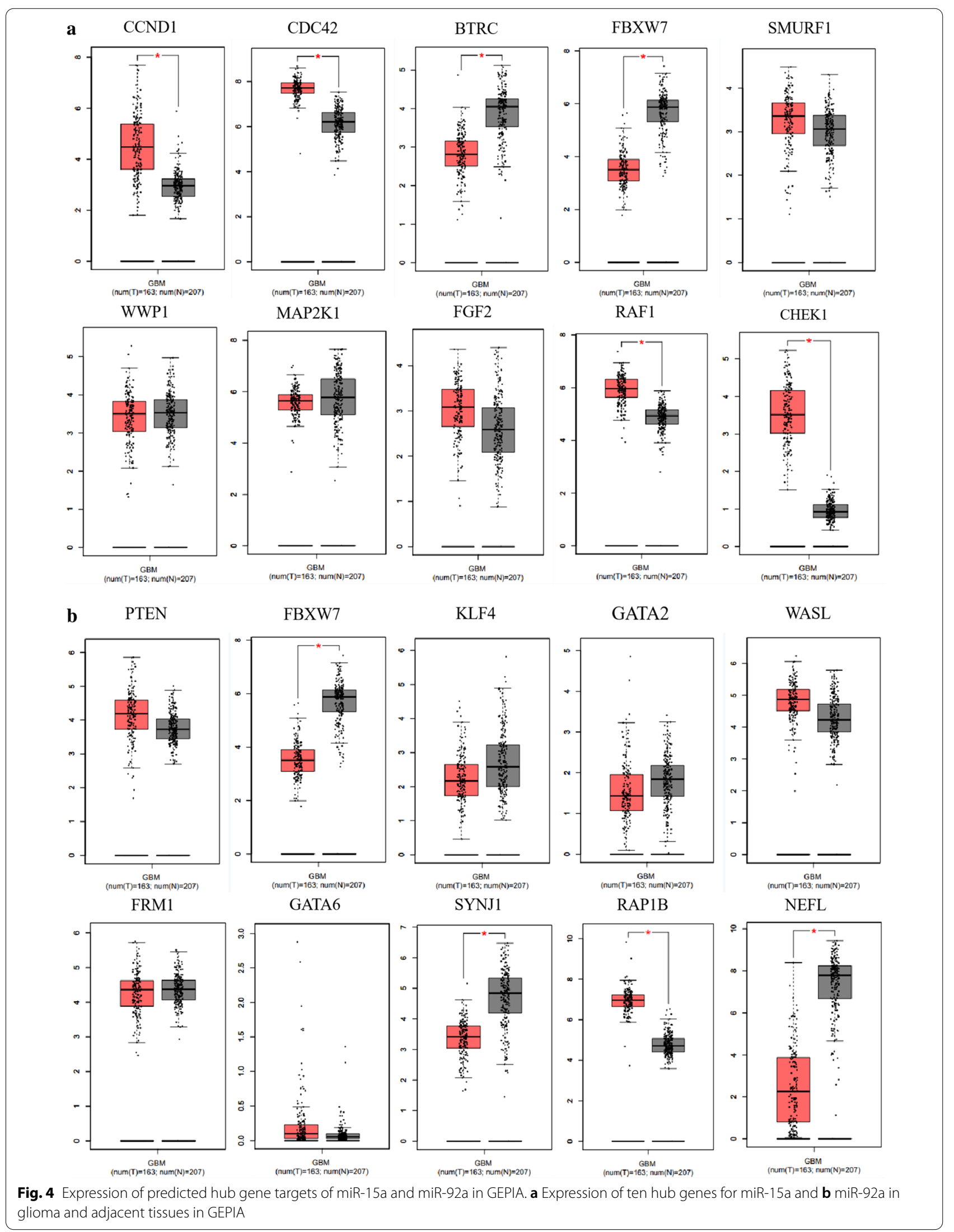


Therefore, these four genes were selected for subsequent research. For miR-92a, we obtained 240 target genes (Additional file 1: Figure S3C), of which ten were identified as hub genes (Additional file 1: Figure S3D). According to the expression in glioma and adjacent tissues in GEPIA, only RAP1B was highly expressed in gliomas (Fig. 4b), which was chosen for following study.

\section{Target gene validation}

In order to verify the target genes obtained from database prediction, we performed qRT-PCR, western blot and dual luciferase reporter gene assays in vitro. We transfected miR-15a, miR-92a and mimic NC into T98 and U251 cells, respectively. The qRT-PCR results showed that the over-expression efficiency of miR-15a in T98 and U251 cells was 11.67 and 8.4 times (Figure S4A), and that of miR-92a was 15.92 and 14.59 times (Additional file 1: Figure S4B), respectively. In addition, we verified the effect of target genes in cells through two different transfection methods of transfecting
miR-15a and miR-92a into M2 type macrophages and collect exosomes or directly transfecting miR-15a and miR-92a into T98 cells. The results indicated that there was no evidently difference (Additional file 1: Figure S5).

After the transfection of miR-15a, only CCND1 was down-regulated in T98 and U251 cell lines among the four predicted target genes (Fig. 5a). Western blot analysis also revealed that miR-15a over-expression could down-regulate the protein expression level of CCND1, so CCND1 was selected as the next research object (Fig. 5b). The relative luciferase activity was decreased in co-transfection of pGL3-CCND1-WT with miR-15a, compared with the control of mimic NC $(\mathrm{p}<0.05)$, and there was no significant difference in luciferase activity in co-transfection of pGL3-CCND1-Mut with miR15a (Fig. $5 \mathrm{c}$ ), indicating that miR-15a was bound to the CCND1 gene. For miR-92a, qRT-PCR and western blot assays confirmed that miR-92a over-expression can down-regulate the gene and protein expression levels
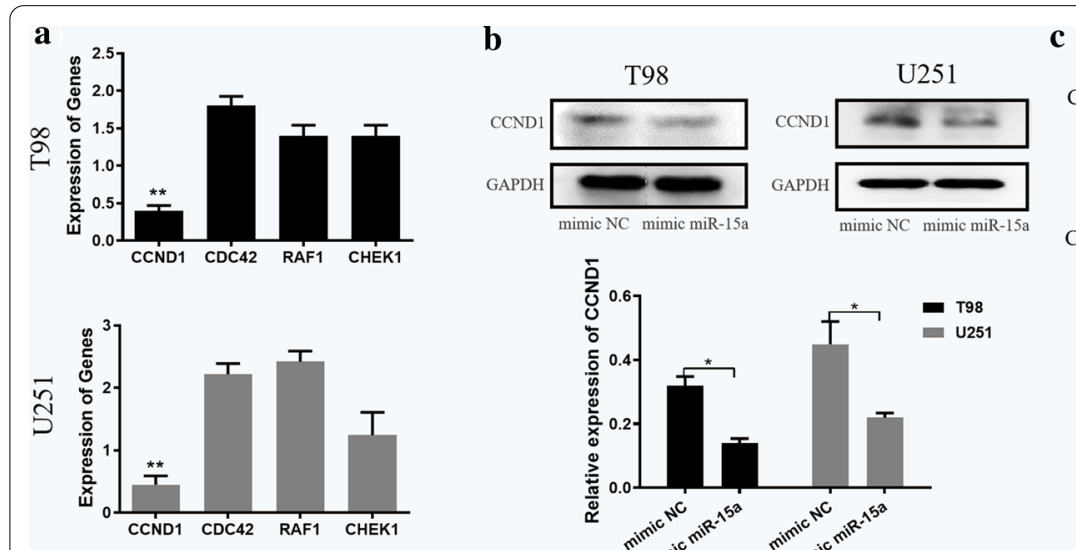

c
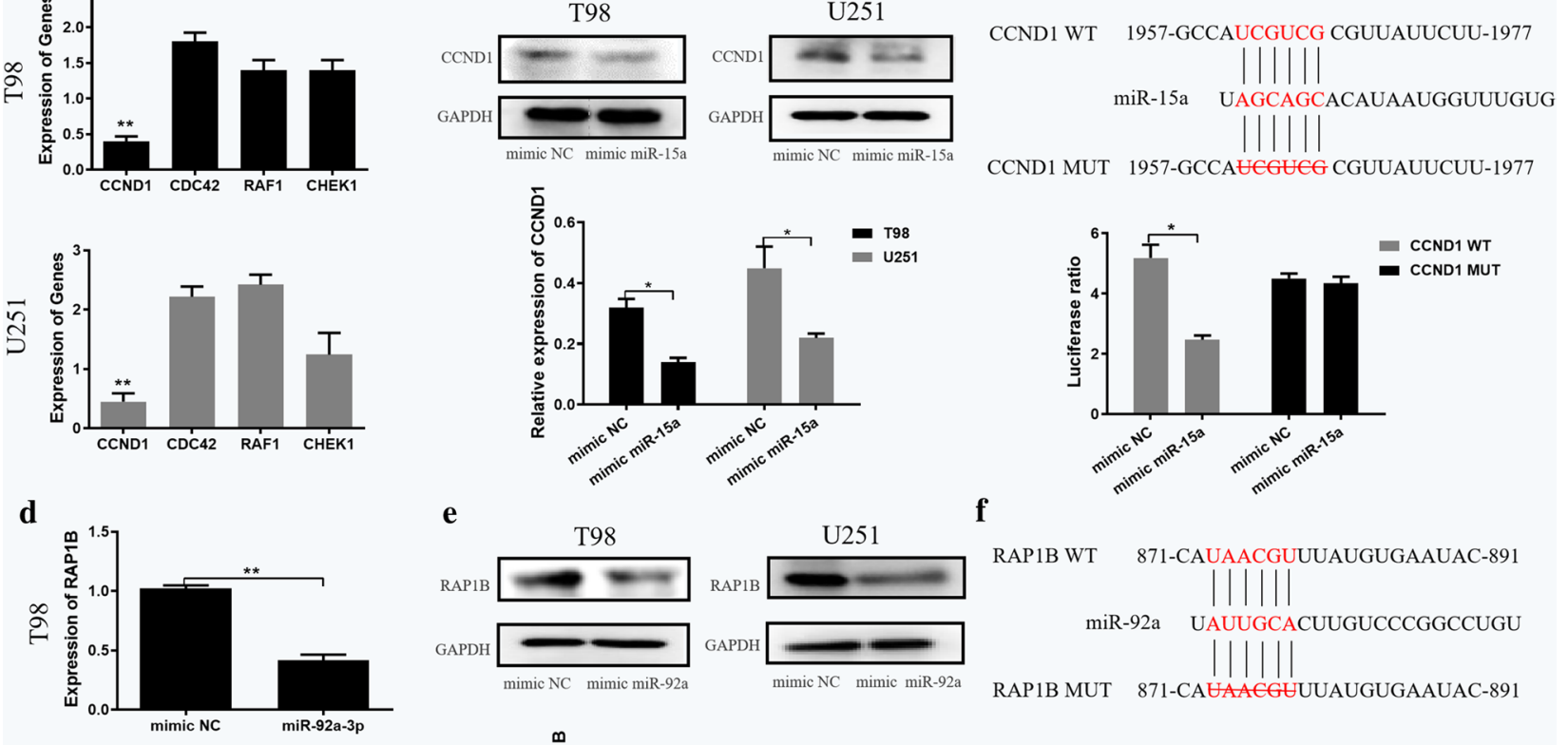

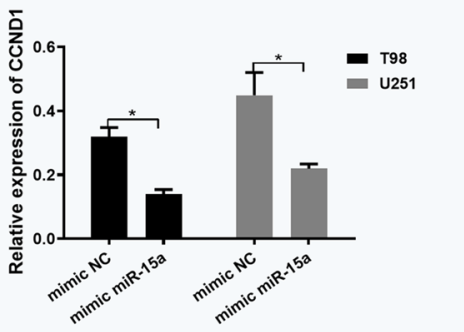

e
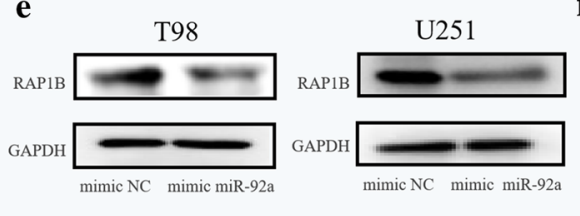

f

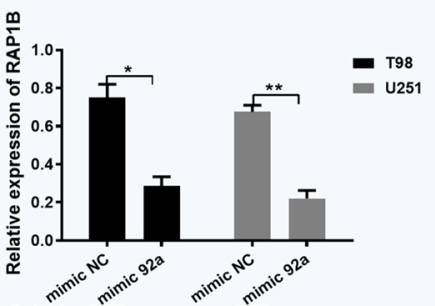

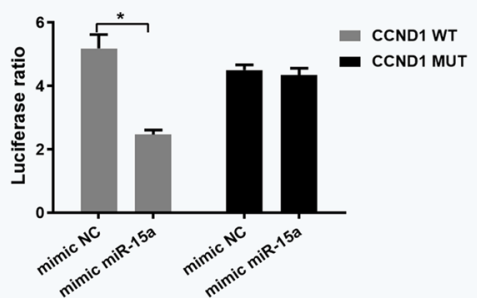

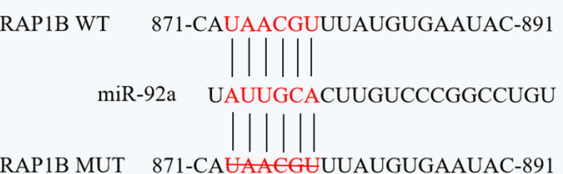

CCND1 MUT 1957-GCCAUCGUCG CGUUAUUCUU-1977

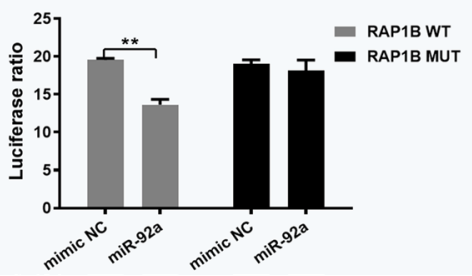

RAPIB MUT 871-CAUAACGEUUAUGUGAAUAC-891

Fig. 5 Target gene validation of miR-15a and miR-92a. Expression of selected target genes of a miR-15a and $\mathbf{d}$ miR-92a in T98 and U251 cell lines as analyzed by qRT-PCR assays. Protein expression of selected target genes of $\mathbf{b}$ miR-15a and $\mathbf{e}$ miR-92a in T98 and U251 cell lines as measured by western blot assays. Effects of $\mathbf{c}$ miR-15a and $\mathbf{f}$ miR-92a on the luciferase reporter activity of cells with CCND1 WT or CCND1 MUT and RAP1B WT or RAP1B MUT, respectively. Error bars denote standard deviation of triplicates. ${ }^{* *} \mathrm{P}<0.01$; ${ }^{*} \mathrm{P}<0.05$. WT: wild type; MUT: mutant type 
of RAP1B (Fig. 5d, e). In addition, the dual luciferase reporter gene assay confirmed that RAP1B was a target of miR-92a (Fig. 5f).

\section{RAP1B and CCND1 can activate the PI3K/AKT/mTOR signaling pathway}

Studies have shown that PI3K/AKT/mTOR signaling pathway is closely related to the regulatory mechanism of glioma. We wondered whether CCND1 and RAP1B could affect the PI3K/AKT/mTOR signaling pathway in glioma. Therefore, si-CCND1 and si-RAP1B were transfected into T98 and U251 cell lines to study the effect of CCND1 and RAP1B on the PI3K/AKT/mTOR signaling pathway. As shown in Fig. 7, CCND1 knockdown in T98 and U251 cell lines reduced the phosphorylation level of AKT and mTOR compared to the NC group. For RAP1B, we obtained similar results by western blot analysis (Fig. 6a and b). Collectively, these results revealed that RAP1B and CCND1 could activate the PI3K/AKT/ mTOR signaling pathway in glioma cells. To demonstrate whether macrophage-derived exosomal miR-15a and
miR-92a have any effect on PI3K/AKT/mTOR signaling pathway in glioma cells. The relevant rescue experiments are performed. As shown in Fig. 7a, miR-15a could block the PI3K/AKT/mTOR signaling pathway. The expression levels of $\mathrm{p}$-mTOR and $\mathrm{p}$-AKT were down-regulated in the miR-15a group. The over-expression of CCND1 in the miR-15a group could reverse the blocking effect of miR$15 \mathrm{a}$ on the signaling pathway and rescue the protein levels of p-mTOR and p-AKT to a certain extent. Similarly, miR-92a could block the PI3K/AKT/mTOR signaling pathway. The expression levels of p-mTOR and p-AKT were down-regulated in the miR-92a group, and overexpression of RAP1B in the miR-92a group could reverse the blocking effect of miR-92a on the signaling pathway, and rescue the protein levels of $\mathrm{p}-\mathrm{mTOR}$ and $\mathrm{p}-\mathrm{AKT}$ to a certain extent (Fig. 7b).

\section{Discussion}

Malignant glioma, the most common cancer of the central nervous system, accounts for around $70 \%$ of malignant primary brain tumors [19]. Patients with malignant

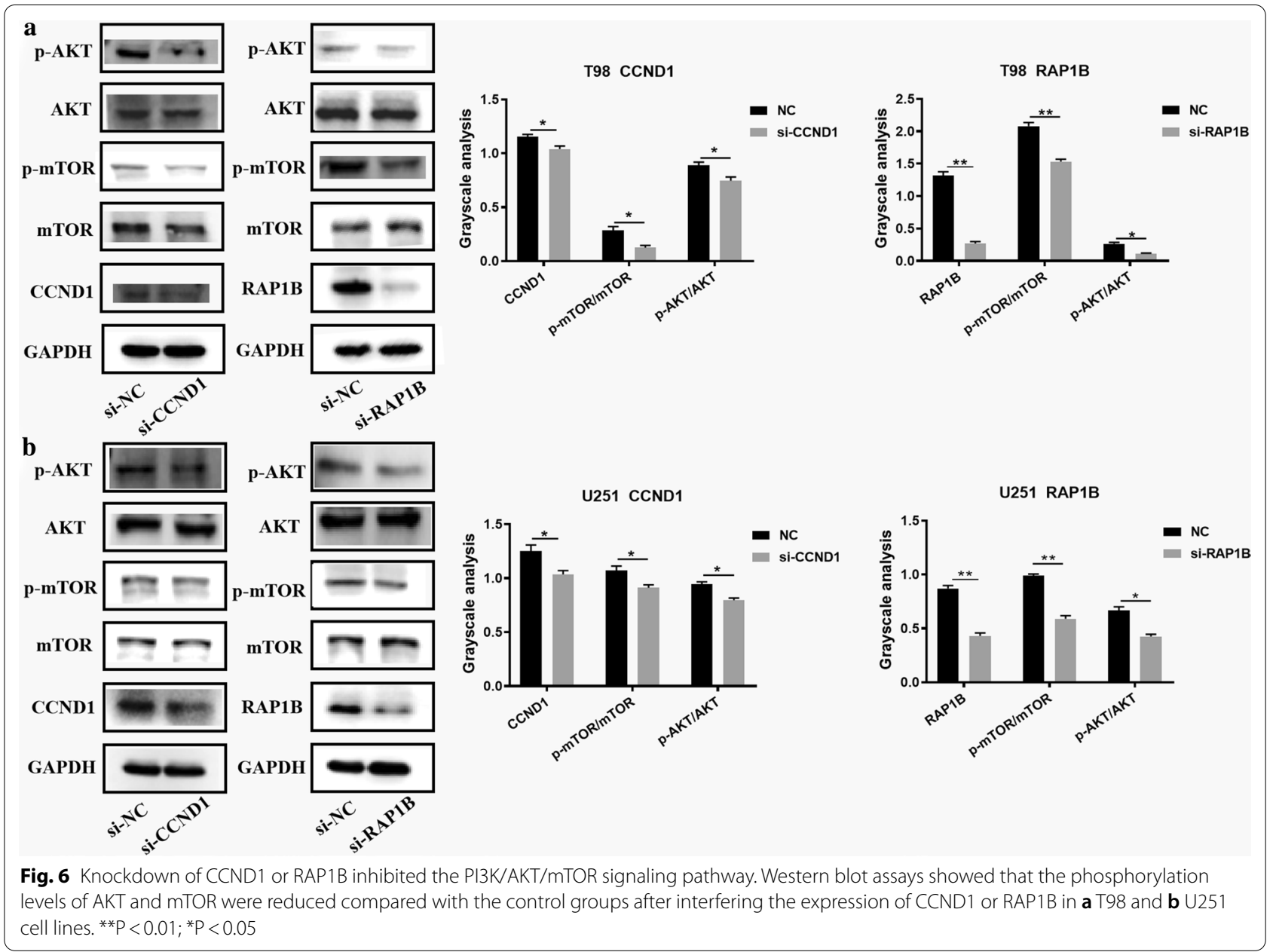




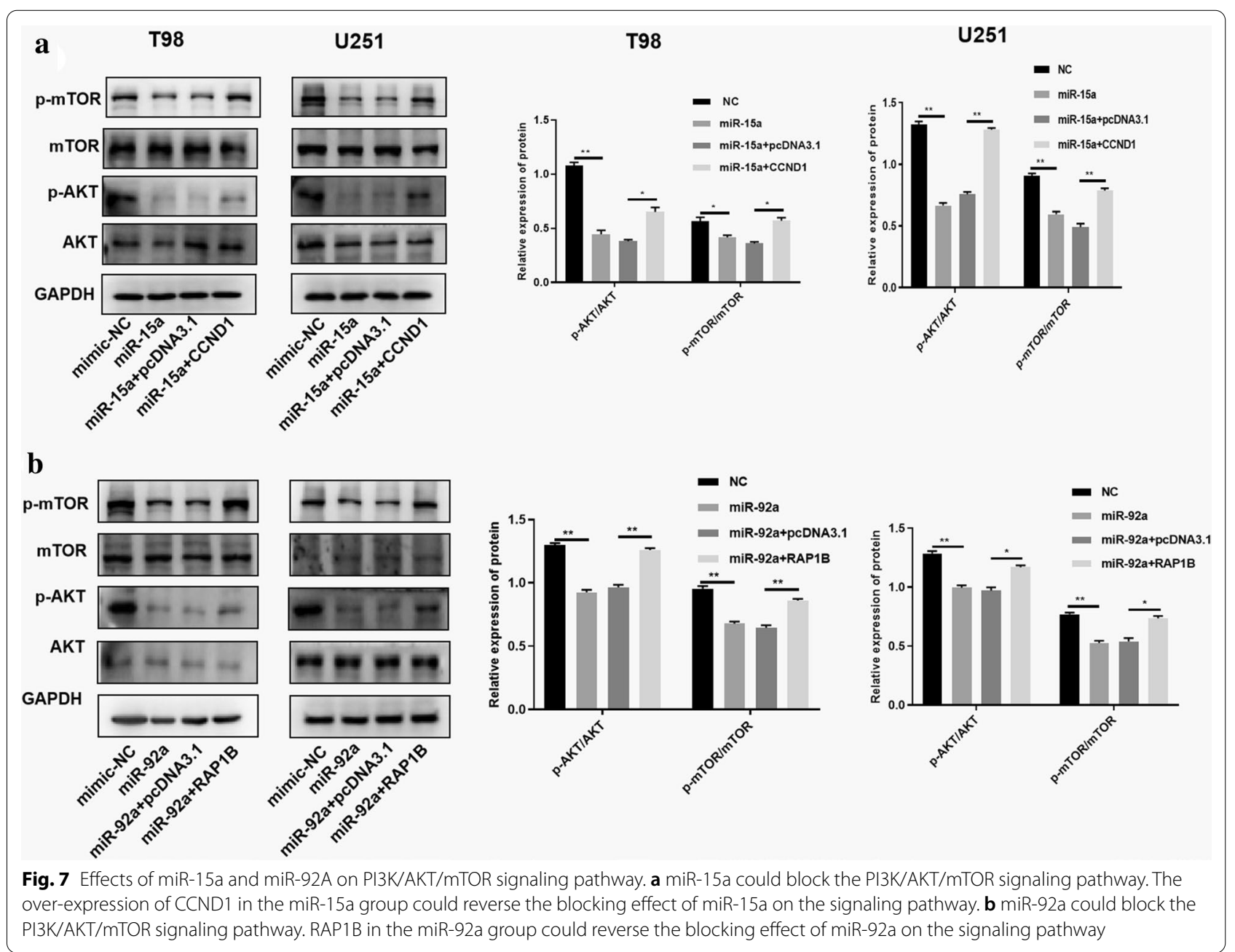

glioma have a poor prognosis, with a median survival time of 3 years [20]. Hence, it is necessary to identify promising biomarkers to help diagnose gliomas early and to develop new therapeutic modalities with favorable prognosis. Exosomal miRNAs have reported to exert important physiological functions in tumorigenesis and development $[17,21]$. In the present study, we identified seven differentially expressed miRNAs in infiltrating macrophages based on dataset GSE51332 from GEO database. Through qRT-PCR detection, miR-15a and miR-92a were found to be under-expressed in M2 macrophages, consistent with the expression levels in GEO. In addition, we confirmed the down-regulation of miR15a and miR-92a in M2 macrophage exosomes. Subsequently, we demonstrated that M2 macrophage-derived exosomes promoted glioma migration and invasion in T98 and U251 cell lines, whereas exosomal miR-15a and miR-92a inhibited the migration and invasion of glioma cells. We thus speculated that miR-15a and miR-92a might inhibit the invasion and migration of gliomas.
According to bioinformatics analysis, we identified four target genes for miR-15a and one for miR-92a. We then selected CCND1 as the key target gene for miR-15a since only CCND1 was down-regulated at the transcript and protein levels after miR-15a was over-expressed. Similarly, RT-qPCR and western blot assays confirmed that miR-92a over-expression was associated with significant reduction in levels of RAP1B transcript and protein. Through dual luciferase reporter gene assays, we verified that CCND1 and RAP1B are the target genes of miR-15a and miR-92a, respectively.

CCND1, namely G1/S-specific cyclin-D1, regulates the cell cycle process during the transition from G1 to $\mathrm{S}$ phase. Increasing studies show that many genes affect the viability and migration of glioma cells by regulating CCND1. For example, Alqudah MA elucidated that via activation of CCND1 and EGFR, NOTCH3 promotes glioma cell proliferation, migration and invasion [22]. Similar to our results, the reduction of miR-17 in glioma cells 
improves cell viability and migration ability by increasing the expression of CCND1, p-Akt and Akt [23].

RAP1B encodes a member of the RAS-like small GTPbinding protein superfamily, which regulates a variety of cellular processes, including cell adhesion, growth, and differentiation [24]. Accumulating data indicate that the deregulated activation of RAP1B is related to a series of malignant tumors, and that RAP1B has effects on cell proliferation, metastasis, angiogenesis, and treatment resistance $[25,26]$. In addition, numerous studies have reported that CCND1/RAP1B is associated with glioma cell proliferation and invasion [27-30]. Consistent with our findings, studies have shown that abnormal miRNA expression can affect gliomas by targeting RAP1B. For example, She et al. demonstrated that overexpression of miR-181 can inhibit the aggressive proliferation of glioblastoma cells by targeting RAP1B-mediated cytoskeletal remodeling and related molecular changes [31].

Furthermore, we demonstrated that knockdown of CCND1 or RAP1B could inhibit the PI3K/AKT/mTOR signaling pathway. Moreover, in the rescue experiment, we found that miR-15a and miR-92a could block the $\mathrm{PI} 3 \mathrm{~K} / \mathrm{AKT} / \mathrm{mTOR}$ signaling pathway. Overexpression of CCND1/RAP1B in miR-15a/miR-92a group can reverse the blocking effect of miR-15a/miR-92a on the signaling pathway, and rescue the phosphorylated protein in a certain extent. It has been demonstrated that many microRNAs as biomarkers for glioblastoma [32-34]. However, recent evidence suggests that microRNAs could migrate between cells and mediate repression of target genes [35].
In addition, miRNAs play a negative regulation and confer characteristic changes in the expression levels of target genes, and may regulate a variety of signaling pathways, and will generate integral effects on recipient cells [36]. To some extent, the above research provides new insights into the mechanism research. p-AKT and p-mTOR were reported to be activated or over-expressed in human gliomas, and the labeling index of the PI3K/AKT/mTOR pathway increased with increasing grade of malignancy $[37,38]$. In gliomas, the PI3K/AKT/mTOR pathway helps to induce invasion and angiogenesis in cells, and patients with activated PI3K/AKT/mTOR pathway have a worse prognosis than those without carcinogenic activation of the pathway $[39,40]$. In addition, BRCA1-associated proteins inhibit glioma cell proliferation and migration through the TGF- AKT/PI3K/mTOR signaling pathway [41] To some extent, the above research [13]. Besides in gliomas, this pathway was involved in the pathological mechanism of other cancer. For example, Xu et al. reported that exosome MALAT1 promotes the malignant behavior of CRC cells by activating the PI3K/Akt/ mTOR pathway [42]. Similarly, the other article reported that Dhw-208 inhibits the growth of human breast cancer cells by inhibiting the PI3K/AKT/MTOR signaling pathway [43]. BRCA1-associated proteins inhibit glioma cell proliferation and migration through the TGF-AKT/PI3K/ mTOR signaling pathway [13].

To better understanding our study, we deduced a mechanism diagram of miR-15a and miR-92a (Fig. 8): M2 macrophages secrete miR-15a and miR-92a to glioma

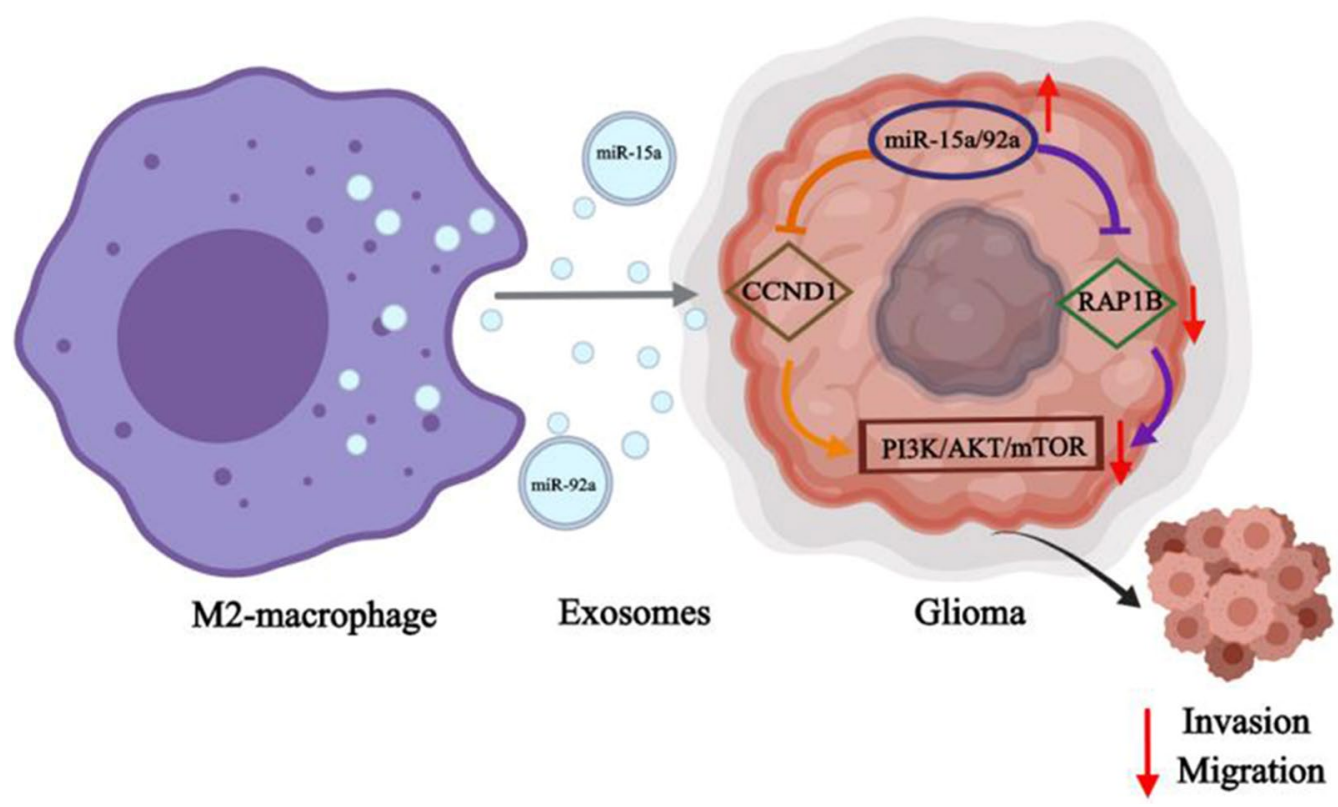

Fig. 8 Mechanism diagram of miR-15a and miR-92a in gliomas 
cells through exosomes, and then miR-15a and miR-92a separately bind to CCND1 and RAP1B, thereby blocking the PI3K/AKT/mTOR signaling pathway to inhibit glioma invasion and migration.

As is well known to all, the main function of M2-type macrophages is to promote the progress of tumor cells. For the first time, our findings elucidated that M2 macrophage-derived miR-15a and miR-92a could be secreted through exosomes to inhibit the invasion and migration of glioma cells. Combining bioinformatics analysis and experiments, CCND1 and RAP1B were found to be the target genes of miR-15a and miR-92a, respectively. To sum up, we unearthed that M2 macrophage-derived miR-15a and miR-92a could target CCND1 and RAP1B, respectively, thereby inhibiting the invasion and migration via blocking $\mathrm{PI} 3 \mathrm{k} / \mathrm{AKT} / \mathrm{mTOR}$ signaling pathway in gliomas. Despite these promising results, the limitations cannot be ignored. In this paper, there is a lack of animal experiments and some rescue experiments for verification. In addition, whether miR-15a and miR-92a can affect the differentiation of macrophages. M1 macrophages mainly play an anti-tumor and pro-inflammatory role, while M2 macrophages chiefly promote tumor progression. If miR-15a and miR-92a can affect the proportion of these two phenotypes of macrophages, they will also play a role in glioma invasion and migration, which will be our future research direction.

\section{Methods}

\section{Cell lines}

Glioma cell lines (T98 and U251) and human mononuclear macrophage line (THP-1) were purchased from Cell Bank of Chinese Academy of Sciences (http://www. cellbank.org.cn/). T98 and U251 cells were incubated in Dulbecco's modified Eagle's medium (DMEM, 31600034, Hyclone, Logan, UT, USA) supplemented with $10 \%$ fetal bovine serum (FBS, 10099141, Gibco, Grand Island, NY, USA). THP-1 cells were treated with $100 \mathrm{ng} / \mathrm{mL}$ phorbol 12-myristate 13-acetate (PMA, P1585, Sigma, St.Louis, Missouri, USA) for $24 \mathrm{~h}$ for differentiation into macrophages. Next, cells were treated with $100 \mathrm{ng} / \mathrm{mL}$ lipopolysaccharide (LPS, P8139, Sigma, St.Louis, Missouri, USA) and $20 \mathrm{ng} / \mathrm{mL}$ interferon- $\gamma$ (IFN- $\gamma, 285-\mathrm{IF}$, R\&D, Minneapolis, MN, USA) for $24 \mathrm{~h}$, polarizing them into M1 phenotype. After treatment with $20 \mathrm{ng} / \mathrm{mL}$ interleukin 4 (IL-4, AF-200-04-5, Peprotech, Rocky Hill, NJ, USA) for $72 \mathrm{~h}$, the cells were polarized to M2 phenotype.

\section{Cell treatment and grouping}

THP-1 was considered as a control group without any transfection, while Exo was considered as an experimental group with M2 macrophage exosomes. Once the cell fusion in T98 and U251 cells reached $80-90 \%$, transfection was performed according to the instructions provided by Lipofectamine 2000 (11668-019, Invitrogen, New York, CA, USA). The cells were grouped into mimic NC (transfection of mimic NC), mimic miR-15a (transfection of miR-15a), and mimic miR-92a (transfection of miR-92a).

\section{Isolation and characterization of exosomes}

Once the confluence of macrophages reached $80-90 \%$, the complete medium was discarded and replaced with fresh medium. Next, we collected $30 \mathrm{~mL}$ of used cell culture medium in each cell line and isolated the exosomes by centrifugation at $4^{\circ} \mathrm{C}$. After additional centrifugation at $4{ }^{\circ} \mathrm{C}$ at $100,000 \mathrm{~g}$ overnight, the exosomes were extracted in accordance with the instructions on the ExoQuick (System Bioscience, Mountain View, CA, USA). The precipitation was then washed with a large amount of PBS, resuspended in PBS and stored at $-80^{\circ} \mathrm{C}$ for further use. The exosomal suspension was concentrated and the concentration of exosomes was measured using the bicinchoninic acid (BCA) kit (23227, Thermo Fisher Scientific, Waltham, MA, USA).

Subsequently, exosomes were identified using JEM2010 HT transmission electron microscope. $20 \mu \mathrm{L}$ of exosomes was added dropwise to a copper mesh and left for $3 \mathrm{~min}$. Then filter paper was used to suck up the liquid from the sides. Next, $30 \mu \mathrm{L}$ of phosphotungstic acid solution ( $\mathrm{pH}$ 6.8) was added to counter-staine exosomes for $5 \mathrm{~min}$ at room temperature. After baking, exosomes were photographed under the transmission electron microscope. Western blot analysis was then used to identify exosomal surface markers, such as tumor susceptibility genes 101 (TSG101), CD63, and CD9.

\section{Transmission electron microscopy (TEM)} and Nanoparticle-trancking analysis (NTA) analysis NTA and TEM were used to identify exosomes from macrophage cell. Exosome sample were added to copper grids at room temperature for $5 \mathrm{~min}$, stained using $2 \%$ uranyl acetate solution for $1 \mathrm{~min}$, dried for $20 \mathrm{~min}$ at room temperature, and then observed using TEM (JEOL, Ltd.). Besides, the size distribution of the exosomes was measured with NanosizerTM technology (Malvern Instruments, Malvern, UK), and was analysed using Zetasizer software (Malvern).

\section{Reverse transcription quantitative polymerase chain reaction (RT-qPCR)}

Total RNA was extracted by Trizol reagent (Invitrogen, Carlsbad, CA) according to the manufacturer's instructions. Reverse transcription was carried out after total RNA was extracted, according to instructions of UEIris II RT-PCR System for First-Strand cDNA Synthesis (US 
Everbright ${ }^{\circledR}$ Inc, Suzhou, China). SYBR Premix Ex Taq (US Everbright ${ }^{\circledR}$ Inc, Suzhou, China) on an ABI 7900 system (Applied Biosystems, Foster City, CA, USA) was employed to conduct qRT-PCR assay using glyceraldehyde 3-phosphate dehydrogenase (GAPDH) as endogenous controls. The $2-\Delta \Delta \mathrm{Ct}$ method was employed to detect the comparative quantification. The primers were purchased from Sangon Biotech (Shanghai, China) and the sequences were shown in Table 2 .

\section{Scratch wound healing assays}

The scratch wound healing assay was used to evaluate the transverse migratory ability of cells. Briefly, $1 \times 106 /$ $\mathrm{mL}$ cells were plated on 6-well plates and scraped by a $10 \mu \mathrm{l}$ tip to generate uniform wounds. The wells were washed three times with phosphate-buffered saline (PBS) to remove the exfoliated cells, and then medium with $2 \%$ fetal bovine serum was added. The cells were further incubated in a $37^{\circ} \mathrm{C}$ and $5 \% \mathrm{CO}_{2}$ incubator. The photos at a magnification of $40 \times$ were taken at $0,24,48$ and $72 \mathrm{~h}$, respectively.

\section{Transwell assays}

Transwell chambers uncoated or coated with Matrigel (BD Biosciences, USA) were employed to assess cell vertical migratory or invasive ability, respectively. In brief, the cells were digested to a concentration of $1 \times 105$ cells/ $\mathrm{ml}$ and seeded in the upper chamber with serum-free medium. At the same time, $600 \mu \mathrm{l}$ of $10 \%$ FBS-DMEM was added to the lower layer. Then exosomes derived from M0/M1/M2 macrophages and M2 macrophages transfected with mimic NC/miR-15a/miR-92a were added to the culture medium in the lower chamber, respectively. After $24 \mathrm{~h}$, the upper device was secured and washed by PBS carefully and then fixed with $4 \%$

Table 2 List of primers used in this study

\begin{tabular}{|c|c|c|}
\hline Name & F Sequences $\left(5^{\prime}-3^{\prime}\right)$ & R Sequences $\left(5^{\prime}-3^{\prime}\right)$ \\
\hline CD206 & ATGTTGAAGGGACGTGGCTG & TCCGTTCACCAGAGGGATCT \\
\hline $\mid \mathrm{L}-10$ & $\begin{array}{l}\text { GACTTTAAGGGTTACCTG } \\
\text { GGTTG }\end{array}$ & TCACATGCGCCTTGATGTCTG \\
\hline TNF-a & AGGCACTCCCCCAAAAGATG & TGGTGGTTTGTGAGTGTGAGG \\
\hline $\mathbb{I L}-12$ & TTGAGGTCATGGTGGATGCC & GGTCAGGTTTGATGATGTCCCT \\
\hline CCND1 & ACAGCGTGAGAGGTACTAGGT & CTTGGGGTCCATGTTCTGCT \\
\hline RAP1B & ACAGCGTGAGAGGTACTAGGT & GTAAATTGCTCCGTTCCTGC \\
\hline GAPDH & GCTCTCTGCTCCTCCTGTTC & CGACCAAATCCGTTGACTCC \\
\hline CDC24 & CGACCGCTGAGTTATCCACA & TCTCAGGCACCCACTTTTCT \\
\hline RAF1 & GATGCCGTGTTTGATGGCTC & CCATTTCGCACATTGACCACT \\
\hline CHEK1 & ATGAAGCGTGCCGTAGACTG & TGCAGATAAACCACCCCTGC \\
\hline
\end{tabular}

F: forward; R: reverse polyformaldehyde for $20 \mathrm{~min}$ at room temperature. Then the chamber was stained in a 24-well plate containing $600 \mu \mathrm{L}$ of crystal violet for $20 \mathrm{~min}$. The inside of chamber was carefully wiped with medical cotton. The cells were then moved to a new 24-well plate, and observed under a microscope at a magnification of $40 \times$.

\section{Western blot analysis}

Total protein of cell or exosome was extracted after $48 \mathrm{~h}$ transfection using cell lysis buffer (Beyotime Biotechnology Shanghai, China). The supernatant was collected after centrifugation $(12,000 \mathrm{rpm})$ at $4{ }^{\circ} \mathrm{C}$ for $15 \mathrm{~min}$. Protein samples were separated using $12 \%$ sodium dodecyl sulfate polyacrylamide gel electrophoresis (SDS-PAGE) after boiling for $10 \mathrm{~min}$ with loading buffer (Beyotime Biotechnology Shanghai, China), and transferred to a polyvinylidene fluoride (PVDF) membrane at $200 \mathrm{~mA}$ for $120 \mathrm{~min}$. After blockade by $5 \% \mathrm{BSA}$ at room temperature for $60 \mathrm{~min}$, blots were probed with diluted primary antibodies: antiCD206 (ab64693, 1:1000), CD68 (ab125212, 1:1000), CD9 (ab223052, 1:1000), CD63 (ab216130, 1:1000), TSG101 (ab30871, 1:1000), CCND1 (ab226977, 1:1000), RAP1B (ab154756,1:1000), p-AKT (ab38449, 1:1000), AKT (ab18785, 1:1000), p-mTOR (ab109268, 1:1000), mTOR (ab2732, 1:1000) and glyceraldehyde-3-phosphate dehydrogenase (GAPDH) $(\mathrm{ab} 8245,1: 5000)$ at $4{ }^{\circ} \mathrm{C}$ overnight. Subsequently, the membrane was incubated with horseradish peroxidase (HRP)-labeled goat anti-rabbit IgG (ab205718, 1:20000) or goat anti-mouse (ab6789, 1:5000) dilution for $1 \mathrm{~h}$ at room temperature. Antibodies were all purchased from Abcam Inc. (Cambridge, UK). The images of the gels were scanned using Bio-Rad Gel Doc XR+system (BioRad, Hercules, CA, USA). GAPDH was used as an internal control. The protein levels were expressed as the ratio of target bands to GAPDH.

\section{Bioinformatics analysis}

We retrieved the gene expression data related to gliomas from GEO database (https://www.ncbi.nlm.nih.gov/geo/) and then performed differential expression analysis with screening conditions of $|\log 2 \mathrm{FC}|>1$ and $P<0.05$ by GEO2R (http://www.ncbi.nlm.nih.gov/geo/geo2r/). Subsequently, the potential target genes of miR-15a and miR-92a were predicted using TargetScan [44], picTar [45], miRanda [46] and PITA [47] databases. Next, we used STRING [48] database (https://string-db.org/) to make the protein-protein interactions of the selected target genes and imported them into Cytoscape [49] to obtain hub genes. The expression of the top 10 hub genes was detected via GEPIA database (http://gepia.cancer-pku.cn/index.html). 


\section{Dual luciferase reporter gene assays}

Targeting relationships of CCND1 and miR-15a, RAP1B and miR-92a were confirmed by the Dual luciferase reporter gene assays, respectively. The wild type (WT) containing the predicted target site, and the mutant type (MUT) with the binding site deleted were amplified and cloned into the pGL3 plasmid to generate pGL3-CCND1WT and pGL3-CCND1-MUT, pGL3-RAP1B-WT and pGL3-RAP1B-MUT vectors. Subsequently, the luciferase vectors were transfected into HEK293T cells together with miR-15a, miR-92a or mimic NC, respectively. After $24 \mathrm{~h}$ transfection, the relative luciferase activity was measured by normalizing the firefly luminescence to the Renilla luminescence using the Dual-Luciferase Reporter Assay System (Promega, Madison, WI, USA) following manufacturer's protocol.

\section{Statistical analysis}

All statistical analyses were carried out using GraphPad Prism 7.0 (La Jolla, CA, USA). Differences between two dependent groups were assessed by the Student $t$ test. As for multiple groups, the comparisons were performed with one-way analysis of variance. $\mathrm{P}<0.05$ was considered to be statistically significant. All data in this work are presented as the mean $\pm \mathrm{SD}$.

\section{Conclusion}

Taken together, the research results in this paper indicated that the exosomes miR-15a and miR-92a derived from M2 macrophages inhibit the migration and invasion of glioma cells through the PI3K/AKT/mTOR signaling pathway (Additional file 2).

\begin{abstract}
Abbreviations
TAM: Tumor-associated macrophages; miRNAs: microRNAs; miR-15a: hsa-miR15a-5p; miR-92a: hsa-miR-92a-3p; qRT-PCR: Quantitative real-time polymerase chain reaction; GAPDH: Glyceraldehyde 3-phosphate dehydrogenase; PBS: Phosphate-buffered saline; SDS-PAGE: Sodium dodecyl sulfate polyacrylamide gel electrophoresis; PVDF: Polyvinylidene fluoride; HRP: Horseradish peroxidase; MUT: Mutant type.
\end{abstract}

\section{Supplementary information}

The online version contains supplementary material available at https://doi. org/10.1186/s12967-021-02766-w.

\section{Additional file 1.}

Additional file 2

\section{Acknowledgements}

We sincerely thank all the participants, and the technical guidance supported by Wuhan Bojie Biomedical Science and Technology CO., LTD. in the study.

\section{Authors' contributions}

$J Y$ and ZW conceived and designed the experiments. YC, CM and YZ participated in this design. YX, XG and ZL revised the manuscripts and the statistical analysis. All authors read and approved the final manuscript.

\section{Funding}

The support in this work was from National Natural Science Foundation of China (81573459), Medical Science Advancement Program of Wuhan University (NO. TFJC2018003), and National Health Commission (2018ZX-07S-011).

\section{Data availability}

The data supporting the findings of this study can be obtained from the corresponding author according to the reasonable request.

\section{Declarations}

\section{Competing interests}

The authors confirm that there are no conflicts of interest in this work.

\section{Author details}

${ }^{1}$ Human Genetic Resources Conservation Center of Hubei Province, Wuhan 430071, China. ${ }^{2}$ Tumor Precision Diagnosis and Treatment Technology and Translation Medicine, Hubei Engineering Research Center, Wuhan 430071, China. ${ }^{3}$ Department of Physiology, Wuhan University School of Basic Medical Sciences, Wuhan 430071, China. ${ }^{4}$ Department of Neurology, Hankou Hospital, General Hospital of Central Theater Command of Chinese People's Liberation Army, Wuhan 430014, China. ${ }^{5}$ Department of Neurosurgery, Zhongnan Hospital of Wuhan University, No 169 Donghu Road, Wuhan 430071, Hubei, China. ${ }^{6}$ Department of Oncology, Zhongnan Hospital of Wuhan University, Wuhan 430071, China. ${ }^{7}$ Department of Neurosurgery, Liaocheng People's Hospital, Liaocheng 252000, China. ${ }^{8}$ Department of Neurosurgery, General Hospital of Northern Theater Command of People's Liberation Army, Shenyang 110000, China.

Received: 21 October 2020 Accepted: 22 February 2021

Published online: 06 March 2021

\section{References}

1. Elsherbiny ME, Emara M, Godbout R. Interaction of brain fatty acidbinding protein with the polyunsaturated fatty acid environment as a potential determinant of poor prognosis in malignant glioma. Prog Lipid Res. 2013;52(4):562-70. https://doi.org/10.1016/j.plipres.2013.08.004.

2. Lee JH, Lee JE, Kahng JY, Kim SH, Park JS, et al. Human glioblastoma arises from subventricular zone cells with low-level driver mutations. Nature. 2018;560(7717):243-7. https://doi.org/10.1038/s41586-018-0389-3.

3. Hou LC, Veeravagu A, Hsu AR, Tse VC. Recurrent glioblastoma multiforme: a review of natural history and management options. Neurosurg Focus. 2006;20(4):E5. https://doi.org/10.3171/foc.2006.20.4.2.

4. Lapointe S, Perry A, Butowski NA. Primary brain tumours in adults. Lancet. 2018;392(10145):432-46. https://doi.org/10.1016/s0140-6736(18)30990-5.

5. Niyazi M, Siefert A, Schwarz SB, Ganswindt U, Kreth FW, et al. Therapeutic options for recurrent malignant glioma. Radiother Oncol. 2011;98(1):1-14. https://doi.org/10.1016/j.radonc.2010.11.006.

6. Engels B, Rowley DA, Schreiber H. Targeting stroma to treat cancers. Semin Cancer Biol. 2012;22(1):41-9. https://doi.org/10.1016/j.semcancer.2011.12. 008.

7. Tlsty TD, Coussens LM. Tumor stroma and regulation of cancer development. Annu Rev Pathol. 2006;1:119-50. https://doi.org/10.1146/annurev. pathol.1.110304.100224.

8. Condeelis J, Pollard JW. Macrophages: obligate partners for tumor cell migration, invasion, and metastasis. Cell. 2006;124(2):263-6. https://doi. org/10.1016/j.cell.2006.01.007.

9. Laoui D, Van Overmeire E, De Baetselier P, Van Ginderachter JA, Raes G. Functional relationship between tumor-associated macrophages and macrophage colony-stimulating factor as contributors to cancer progression. Front Immunol. 2014;5:489. https://doi.org/10.3389/fimmu.2014. 00489.

10. Martinez FO, Helming L, Gordon S. Alternative activation of macrophages: an immunologic functional perspective. Annu Rev Immunol. 2009;27:45183. https://doi.org/10.1146/annurev.immunol.021908.132532.

11. Mosser DM, Edwards JP. Exploring the full spectrum of macrophage activation. Nat Rev Immunol. 2008;8(12):958-69. https://doi.org/10.1038/ nri2448. 
12. Mantovani A, Sica A. Macrophages, innate immunity and cancer: balance, tolerance, and diversity. Curr Opin Immunol. 2010;22(2):231-7. https:// doi.org/10.1016/j.coi.2010.01.009.

13. Bao L, Li X. MicroRNA-32 targeting PTEN enhances M2 macrophage polarization in the glioma microenvironment and further promotes the progression of glioma. Mol Cell Biochem. 2019;460(1-2):67-79. https://doi. org/10.1007/s11010-019-03571-2.

14. Zhu C, Mustafa D, Zheng PP, van der Weiden M, Sacchetti A, et al. Activation of CECR1 in M2-like TAMs promotes paracrine stimulation-mediated glial tumor progression. Neuro Oncol. 2017;19(5):648-59. https://doi.org/10. 1093/neuonc/now2510.

15. Mashouri L, Yousefi H, Aref AR, Ahadi AM, Molaei F, et al. Exosomes: composition, biogenesis, and mechanisms in cancer metastasis and drug resistance. Mol Cancer. 2019;18(1):75. https://doi.org/10.1186/s12943-019-0991-5.

16. Tkach $M$, Thery C. Communication by extracellular vesicles: where we are and where we need to go. Cell. 2016;164(6):1226-32. https://doi.org/10. 1016/j.cell.2016.01.043.

17. Lan J, Sun L, Xu F, Liu L, Hu F, et al. M2 macrophage-derived exosomes promote cell migration and invasion in colon cancer. Cancer Res. 2019;79(1):146-58. https://doi.org/10.1158/0008-5472.can-18-0014.

18. Zheng P, Luo Q, Wang W, Li J, Wang T, et al. Tumor-associated macrophagesderived exosomes promote the migration of gastric cancer cells by transfer of functional Apolipoprotein E. Cell Death Dis. 2018;9(4):434. https://doi.org/ 10.1038/s41419-018-0465-5.

19. Wen PY, Kesari S. Malignant gliomas in adults. N Engl J Med. 2008;359(5):492-507. https://doi.org/10.1056/NEJMra0708126.

20. Chamberlain MC. Emerging clinical principles on the use of bevacizumab for the treatment of malignant gliomas. Cancer. 2010;116(17):3988-99. https://doi.org/10.1002/cncr.25256.

21. Kanlikilicer P, Bayraktar R, Denizli M, Rashed MH, Ivan C, et al. Exosomal miRNA confers chemo resistance via targeting Cav1/p-gp/M2-type macrophage axis in ovarian cancer. EBioMedicine. 2018;38:100-12. https://doi. org/10.1016/j.ebiom.2018.11.004.

22. Alqudah MA, Agarwal S, AI-Keilani MS, Sibenaller ZA, Ryken TC, et al. NOTCH3 is a prognostic factor that promotes glioma cell proliferation, migration and invasion via activation of CCND1 and EGFR. PLOS ONE. 2013;8(10):e77299. https://doi.org/10.1371/journal.pone.0077299.

23. Sun G, SiMa G, Wu C, Fan Y, Tan Y, et al. Decreased MiR-17 in glioma cells increased cell viability and migration by increasing the expression of Cyclin D1, p-Akt and Akt. PLoS ONE. 2018;13(1):e0190515. https://doi.org/10.1371/ journal.pone.0190515.

24. Rangarajan S, Enserink JM, Kuiperij HB, de Rooij J, Price LS, et al. Cyclic AMP induces integrin-mediated cell adhesion through Epac and Rap1 upon stimulation of the beta 2-adrenergic receptor. J Cell Biol. 2003;160(4):487-93. https://doi.org/10.1083/jcb.200209105.

25. Malchinkhuu E, Sato K, Maehama T, Ishiuchi S, Yoshimoto Y, et al. Role of Rap1B and tumor suppressor PTEN in the negative regulation of lysophosphatidic acid-induced migration by isoproterenol in glioma cells. Mol Biol Cell. 2009;20(24):5156-65. https://doi.org/10.1091/mbc.e09-08-0692.

26. Zhang L, Cui M, Song L, Zhang M, Zhang J. Function, Significance, and Regulation of Rap1b in Malignancy. Crit Rev Eukaryot Gene Expr. 2019;29(2):151-60. https://doi.org/10.1615/CritRevEukaryotGeneExpr.20190 25997.

27. Chen DG, Zhu B, Lv SQ, Zhu H, Tang J, et al. Inhibition of EGR1 inhibits glioma proliferation by targeting CCND1 promoter. J Exp Clin Cancer Res. 2017;36(1):186. https://doi.org/10.1186/s13046-017-0656-4.

28. Ji QK, Ma JW, Liu RH, Li XS, Shen FZ, et al. CDCA7L promotes glioma proliferation by targeting CCND1 and predicts an unfavorable prognosis. Mol Med Rep. 2019;20(2):1 149-56. https://doi.org/10.3892/mmr.2019.10349.

29. Wan J, Guo AA, Chowdhury I, Guo S, Hibbert J, et al. TRPM7 Induces Mechanistic Target of Rap $1 \mathrm{~b}$ Through the Downregulation of miR-28-5p in Glioma Proliferation and Invasion. Frontiers in Oncology. 2019;9:1413. https://doi. org/10.3389/fonc.2019.01413.

30. Zhao L, Tang X, Luo R, Duan J, Wang Y, et al. MicroRNA-490-5P targets CCND1 to suppress cellular proliferation in glioma cells and tissue through cell cycle arrest. Curr Neurovasc Res. 2018;15(3):246-55. https://doi.org/10. 2174/1567202615666180813130143.

31. She X, Yu Z, Cui Y, Lei $Q$, Wang Z, et al. miR-181 subunits enhance the chemosensitivity of temozolomide by Rap1B-mediated cytoskeleton remodeling in glioblastoma cells. Med Oncol. 2014;31(4):892. https://doi.org/10.1007/ s12032-014-0892-9.
32. Saadatpour L, Fadaee E, Fadaei S, Nassiri Mansour R, Mohammadi M, et al. Glioblastoma: exosome and microRNA as novel diagnosis biomarkers. Cancer Gene Ther. 2016;23(12):415-8. https://doi.org/10.1038/cgt.2016.48

33. Wei X, Chen D, Lv T, Li G, Qu S. Serum MicroRNA-125b as a potential biomarker for glioma diagnosis. Mol Neurobiol. 2016;53(1):163-70. https://doi. org/10.1007/s1 2035-014-8993-1.

34. Xing W, Zeng C. A novel serum microRNA-based identification and classification biomarker of human glioma. Tumour Biol. 2017:39(5):1010428317705339. https://doi.org/10.1177/1010428317705339.

35. Alexander M, Hu R, Runtsch MC, Kagele DA, Mosbruger TL, et al. Exosomedelivered microRNAs modulate the inflammatory response to endotoxin. Nat Commun. 2015;6:7321. https://doi.org/10.1038/ncomms8321.

36. Zhang J, Li S, Li L, Li M, Guo C, et al. Exosome and exosomal microRNA: trafficking, sorting, and function. Genom Proteom Bioinform. 2015;13(1):17-24. https://doi.org/10.1016/j.gpb.2015.02.001

37. Annovazzi L, Mellai M, Caldera V, Valente G, Tessitore L, et al. mTOR, S6 and AKT expression in relation to proliferation and apoptosis/autophagy in glioma. Anticancer Res. 2009;29(8):3087-94.

38. $L i X Y$, Zhang $L Q$, Zhang $X G$, Li X, Ren YB, et al. Association between AKT/ mTOR signalling pathway and malignancy grade of human gliomas. J Neurooncol. 2011;103(3):453-8. https://doi.org/10.1007/s11060-010-0424-1.

39. Chakravarti A, Zhai G, Suzuki Y, Sarkesh S, Black PM, et al. The prognostic significance of phosphatidylinositol 3-kinase pathway activation in human gliomas. J Clin Oncol. 2004;22(10):1926-33. https://doi.org/10.1200/jco. 2004.07.193.

40. Yoshioka K, Yoshida K, Cui H, Wakayama T, Takuwa N, et al. Endothelial PI3KC2alpha, a class II PI3K, has an essential role in angiogenesis and vascular barrier function. Nat Med. 2012;18(10):1560-9. https://doi.org/10.1038/nm. 2928.

41. Wang B, Cao C, Liu X, He X, Zhuang H, Wang D, Chen B, et al. BRCA1-associated protein inhibits glioma cell proliferation and migration and glioma stem cell self-renewal via the TGF- $\beta / P$ I3K AKT/mTOR signalling pathway. Cell Oncol. 2020;43(2):223-35. https://doi.org/10.1007/s13402-019-00482-8.

42. Xu J, Xiao Y, Liu B, Pan S, Liu Q, et al. Exosomal MALAT1 sponges miR$26 \mathrm{a} / 26 \mathrm{~b}$ to promote the invasion and metastasis of colorectal cancer via FUT4 enhanced fucosylation and PI3K/Akt pathway. J Exp Clin Cancer Res. 2020;39(1):54. https://doi.org/10.1186/s13046-020-01562-6.

43. Wang S, Zhang Y, Ren T, Wu Q, Lu H, et al. A novel 4-aminoquinazoline derivative, DHW-208, suppresses the growth of human breast cancer cells by targeting the PI3K/AKT/mTOR pathway. Cell Death \& Disease. 2020;11(6):491. https://doi.org/10.1038/s41419-020-2690-y.

44. Andrews MC, Cursons J, Hurley DG, Anaka M, Cebon JS, et al. Systems analysis identifies miR-29b regulation of invasiveness in melanoma. Mol Cancer. 2016;15(1):72. https://doi.org/10.1186/s12943-016-0554-y.

45. Li P, Chen Y, Juma CA, Yang C, Huang J, et al. Differential inhibition of target gene expression by human microRNAs. Cells. 2019. https://doi.org/10.3390/ cells8080791.

46. Zhang H, Li W, Gu W, Yan Y, Yao X, et al. MALAT1 accelerates the development and progression of renal cell carcinoma by decreasing the expression of miR-203 and promoting the expression of BIRC5. Cell Prolif. 2019;52(5):e12640. https://doi.org/10.1111/cpr.12640.

47. Ma YJ, Yang J, Fan XL, Zhao HB, Hu W, et al. Cellular microRNA let-7c inhibits M1 protein expression of the H1N1 influenza A virus in infected human lung epithelial cells. J Cell Mol Med. 2009;16(10):2539-46. https://doi.org/10. 1111/j.1582-4934.2012.01572.x.

48. Szklarczyk D, Morris JH, Cook H, Kuhn M, Wyder S, et al. The STRING database in 2017: quality-controlled protein-protein association networks, made broadly accessible. Nucleic Acids Res. 2017;45(D1):D362-d368. https://doi. org/10.1093/nar/gkw937.

49. Shannon P, Markiel A, Ozier O, Baliga NS, Wang JT, et al. Cytoscape: a software environment for integrated models of biomolecular interaction networks. Genome Res. 2003;13(11):2498-504. https://doi.org/10.1101/gr. 1239303.

\section{Publisher's Note}

Springer Nature remains neutral with regard to jurisdictional claims in published maps and institutional affiliations. 